\title{
Inhaled Corticosteroids Do Not Influence the Early Inflammatory Response and Clinical Presentation of Hospitalized Subjects With COPD Exacerbation
}

\author{
Ernesto Crisafulli MD PhD, Mónica Guerrero MD, Rosario Menéndez MD PhD, \\ Arturo Huerta MD MSc, Raquel Martinez MD, Alexandra Gimeno RN, \\ Néstor Soler MD, and Antoni Torres MD PhD
}

\begin{abstract}
BACKGROUND: Inhaled corticosteroids are anti-inflammatory medications that can down-regulate the immunologic response in patients with COPD; however, their role at onset of COPD exacerbation is still not understood. The aim of this study was to assess the early inflammatory response and clinical presentation of patients with COPD exacerbation mediated by inhaled corticosteroids. METHODS: Prospective data were collected on 123 hospitalized subjects with COPD exacerbation over a 30-month period at 2 Spanish university hospitals. Based on domiciliary use, comparative analyses were performed between subjects who did not use inhaled corticosteroids $(n=58)$ and subjects who did $(n=65)$. Measurements of serum biomarkers were recorded on admission to the hospital (day 1 ) and on day 3; clinical, physiological, microbiological, and severity data and mortality/readmission rates were also recorded. RESULTS: At days 1 and 3, both groups showed a similar inflammatory response; fluticasone produced lower levels of interleukin-8 compared with budesonide $(P<.01)$. All clinical features considered were similar in the 2 groups; multivariate analysis predicting clinical complications on hospitalization showed air-flow obstruction severity as the only predictive factor (odds ratio $3.13,95 \%$ CI $1.13-8.63, P=.02$ ). CONCLUSIONS: Our study demonstrates a lack of inhaled corticosteroid influence in the early systemic inflammatory response to and clinical presentation of COPD exacerbation. Key words: chronic obstructive pulmonary disease; exacerbation; inhaled corticosteroids; systemic inflammation; clinical presentation. [Respir Care 2014;59(10):1550-1559. (C) 2014 Daedalus Enterprises]
\end{abstract}

\section{Introduction}

The natural course of COPD is characterized by episodic events recognized as COPD exacerbation ${ }^{1}$ and clinically defined by specific respiratory symptoms and signs (increased shortness of breath, increased sputum volume, and purulence). ${ }^{2}$ COPD exacerbation, which often requires

\footnotetext{
Dr Crisafulli is affiliated with the Cardio-Thoracic Department, Pneumology and Respiratory Intensive Care Unit, Carlo Poma Hospital, Mantua, Italy. Drs Guerrero, Huerta, Soler, and Torres are affiliated with the Pneumology Department, Clinic Institute of Thorax, Hospital Clinic of Barcelona, Institut d'Investigacions Biomèdiques August Pi i Sunyer, University of Barcelona, Barcelona, Spain. Drs Menéndez and Martinez and Ms Gimeno are affiliated with the Pneumology Department, Hospital Universitario y Politecnico La Fe, Centro de Investigación Biomédica en Red de Enfermedades Respiratorias, Valencia, Spain.
}

hospitalization, ${ }^{3}$ appears in the clinical evolution of COPD to accelerate the progressive decline in lung impairment, ${ }^{4}$ thereby reducing quality of life $^{5}$ and increasing risk of death. ${ }^{6}$

Although the biologic mechanisms of COPD exacerbation are still not fully understood, some evidence suggests that an activation of first-line defense (airway epithelial

\footnotetext{
This work was supported by the Centro de Investigación Biomédica en Red de Enfermedades Respiratorias and by La Marató TV3. The authors have disclosed no conflicts of interest.

Correspondence: Antoni Torres MD PhD, Pneumology Department, Clinic Institute of Thorax, Hospital Clinic, Villarroel 170, 08036 Barcelona, Spain. E-mail: atorres@clinic.ub.es.
}

DOI: $10.4187 /$ respcare.03036 
cells and alveolar macrophages) releases chemotactic factors by bacterial/viral pathogens or noninfectious triggered stimuli $^{7}$ and leads to the recruitment of neutrophils, with the secretion of a wide range of pro-inflammatory cytokines, thereby causing a further amplification of systemic and local processes. ${ }^{8,9}$ Change in inflammatory biomarker levels from a steady state may define COPD exacerbation onset, clinical course, severity, and prognosis of hospitalized patients. ${ }^{10,11}$

Inhaled corticosteroids are potent anti-inflammatory nonspecific medications that can modulate the systemic immune response of stable COPD patients, ${ }^{12}$ but their role in the efficacy of treatment remains a subject of debate. ${ }^{13} \mathrm{In}$ hospitalized COPD patients with community-acquired pneumonia, inhaled corticosteroids protect against more severe forms ${ }^{14}$ and against complicated pleural effusion. ${ }^{15}$ These beneficial effects in community-acquired pneumonia may be explained by down-regulation of the inflammatory response.

Depending on the severity of COPD and the definition of exacerbation used, inhaled corticosteroids promote a reduction in the frequency of events in patients with COPD exacerbation ${ }^{16,17}$; however, information evaluated at onset in inhaled corticosteroid-mediated systemic inflammatory profiles is still lacking in the field of acute respiratory medicine with regard to COPD exacerbation.

With regard to the risk correlating to chronic use of inhaled corticosteroids, 2 recent reviews performed in large cohorts of stable COPD subjects confirmed an increased risk of developing pneumonia, but not an increased risk of death. ${ }^{18,19}$ Moreover, another large study followed stable COPD subjects for a period of $5 \mathrm{y}$ and showed that the risk of severe pneumonia was strictly dose-related to exposure of inhaled corticosteroids and was higher in patients who had used fluticasone in comparison with budesonide. ${ }^{20}$

We hypothesized that chronic domiciliary treatment with inhaled corticosteroids would influence the early systemic inflammatory response of COPD exacerbation and have an impact on clinical presentation and patient outcome. The primary aim of our observational study was therefore to assess serum levels of pro-inflammatory systemic biomarkers in hospitalized subjects with COPD exacerbation according to non-use or use of inhaled corticosteroids. In addition, we also assessed the clinical characteristics of 2 groups of subjects with COPD exacerbation.

\section{Methods}

\section{Subject Recruitment and Definitions}

Over a period of 30 months (January 2004 to June 2006), we collected prospective data on consecutive adult subjects with COPD exacerbation hospitalized at 2 tertiary university hospitals in Spain (Hospital Universitario y Po-

\section{QUICK LOOK}

\section{Current knowledge}

Inhaled corticosteroids are anti-inflammatory medications intended to modulate the systemic immune response of stable COPD patients. The role of inhaled corticosteroids during exacerbations of COPD is controversial.

\section{What this paper contributes to our knowledge}

The use of inhaled corticosteroids did not influence the early inflammatory response to a COPD exacerbation, and there was no difference in infection rates between subjects using or not using corticosteroids. Baseline COPD severity predicts the complications on admission for a COPD exacerbation.

litecnico La Fe in Valencia and Hospital Clinic in Barcelona). The ethics committees of both hospitals (Projects CEIC 2003/0048 and CEIC 2004/1855, respectively) approved the study, which was conducted in accordance with the Declaration of Helsinki. Written informed consent to obtain biological samples was obtained from selected subjects. Figure 1 shows the study flow diagram.

In accordance with the guidelines of the Global Initiative for Chronic Obstructive Lung Disease (GOLD), ${ }^{1}$ an expert physician specializing in respiratory medicine defined the diagnosis and severity of COPD. Spirometry was performed at least 6 months prior to COPD exacerbationrelated admission and in a stable phase of the disease. A threshold of 10 pack-years was considered as a positive smoking habit. FEV 1 and FVC were assessed via an automated spirometer with predicted values according to the Quanjer equation. ${ }^{21}$

The occurrence of COPD exacerbation was defined according to Anthonisen criteria, based on an acute increase in dyspnea, sputum volume, and sputum purulence. ${ }^{2}$ Subjects were then classified as follows: COPD exacerbation type I, subjects with all 3 symptoms; type II, subjects with 2 symptoms; and type III, subjects with one symptom. ${ }^{2}$

\section{Exclusion Criteria}

Subjects with a documented history of concomitant chronic respiratory conditions (asthma and bronchiectasis) and subjects with COPD but with a domiciliary use of oral corticosteroids in the past 6 months were excluded from the study. Subjects in whom suspected community-acquired pneumonia and acute heart failure were identified clinically and by chest $\mathrm{x}$-ray were also excluded. 


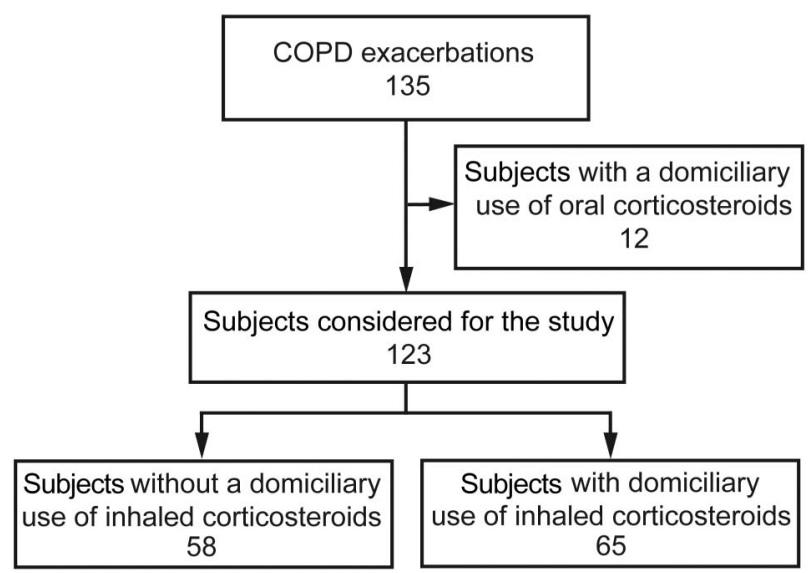

Fig. 1. Study flow diagram.

\section{Use of Inhaled Corticosteroids}

Data on inhaled corticosteroid treatment (yes/no and types of medication) were collected on enrollment. Subjects who received inhaled corticosteroids administered at home before enrollment were classified as inhaled corticosteroid users, whereas subjects who had not received inhaled corticosteroids were classified as no-inhaled corticosteroid users.

\section{Microbiological Sample Collection}

Sputum from subjects with COPD exacerbation was obtained by spontaneous cough on day 1 of admission to the hospital. Gram stain and sputum culture were processed only if the sample was adequate. Sputum was considered valid if the sample contained a count of $>25$ leukocytes and $<10$ epithelial cells per field. When spontaneous cough and sputum collection were not possible, induced sputum production was obtained by inhalation of a $5 \%$ hypertonic saline solution for a period of 5-10 min; the hypertonic saline solution was delivered via a nebulizer device (UltraNeb 2000, DeVilbiss Healthcare, Somerset, Pennsylvania) attached to oxygen. Subjects were then encouraged to cough and expectorate into a sterile plastic container. Spontaneous as well as induced sputum was collected for microbiology diagnosis.

\section{Clinical Measurements}

Data on demographic variables, presence of comorbid conditions (heart, renal, neurologic, and liver diseases; diabetes; and non-active cancer), dyspnea grade according to the Modified Medical Research Council dyspnea scale, prevalence of long-term oxygen therapy, and use of domiciliary bronchodilators (short-acting $\beta_{2}$ agonists, long- acting $\beta_{2}$ agonists, anticholinergics) and theophylline were recorded on admission to the hospital. Characteristics of exacerbations occurring in the preceding year (general rate and rate of subjects requiring hospitalization) were also recorded.

Symptoms and signs of COPD exacerbation (fever, chills, cough, sputum characteristics), physiological data (breathing frequency, heart rate, systolic and diastolic blood pressures), and laboratory data (white blood cell counts, hematocrit, glycemia, creatinine, sodium, potassium) were collected at onset of exacerbation.

Variables for gas impairment, including $\mathrm{pH}, \mathrm{P}_{\mathrm{aCO}_{2}}$, $\mathrm{P}_{\mathrm{aO}_{2}} / \mathrm{F}_{\mathrm{IO}_{2}}$, serum bicarbonate, and base excess, were also collected on admission.

Hospital stay, number of subjects admitted to the ICU or in whom noninvasive ventilation (NIV) support was required, number of subjects in whom shock or mental status alteration was identified, number of subjects using systemic corticosteroids and antibiotics during hospital course, number of classes of antibiotics used, duration of antibiotic treatment (d), doses of systemic corticosteroids per subjects' mortality during hospitalization, and readmission within $30 \mathrm{~d}$ after discharge were also recorded.

\section{Determination of Serum Biomarkers}

Measurements of C-reactive protein, procalcitonin, tumor necrosis factor alpha, and cytokines (interleukin (IL)-1, IL-6, IL-8, and IL-10) were performed on admission to the hospital (day 1) and 3 d after admission (day 3); all biological samples were centralized to the Hospital Clinic.

C-reactive protein was measured by a commercially available immunoturbidimetric method (Bayer Diagnostics, Leverkusen, Germany), whereas procalcitonin was measured using an immunoluminometric technique with a LUMItest assay (Brahms Diagnostica GmbH, Hennigsdorf, Germany).

A microtiter plate with antibody-coated wells was used to measure levels of tumor necrosis factor alpha, IL-1, IL-6, IL-8, and IL-10. Tumor necrosis factor alpha/IL-6 and IL-1/IL-8/IL-10 were determined using the Medgenix (Fleurus, Belgium) and PerSeptive (Framingham, Massachusetts) commercial enzyme immunoassays, respectively.

Reference values of collected serum biomarkers were defined as follows: C-reactive protein, $8 \mathrm{mg} / \mathrm{dL}$; procalcitonin, $0.5 \mathrm{ng} / \mathrm{mL}$; tumor necrosis factor alpha, $20 \mathrm{pg} / \mathrm{mL}$; IL-1, 5 pg/mL; IL-6, < 5 pg/mL; IL-8, 15 pg/mL; and IL$10,5 \mathrm{pg} / \mathrm{mL}$.

\section{Statistical Analysis}

A prior Shapiro-Wilk test for normal data distribution was performed. Results were expressed as mean \pm SD or 
Table 1. General Characteristics of Subjects Enrolled

\begin{tabular}{|c|c|c|c|c|}
\hline Variables & $\begin{array}{l}\text { All Subjects } \\
(n=123)\end{array}$ & $\begin{array}{l}\text { No-Inhaled } \\
\text { Corticosteroid } \\
\text { Subjects } \\
(n=58)\end{array}$ & $\begin{array}{l}\text { Inhaled } \\
\text { Corticosteroid } \\
\text { Subjects } \\
(n=65)\end{array}$ & $P$ \\
\hline Age, y & $69.4 \pm 9.8$ & $68.9 \pm 9.7$ & $69.8 \pm 10$ & .63 \\
\hline Male, $\%$ & 93.4 & 93.1 & 93.8 & .86 \\
\hline Current/former smoking habit, $\%$ & $29.3 / 70.7$ & $27.6 / 72.4$ & $30.8 / 69.2$ & .74 \\
\hline $\mathrm{FEV}_{1}, \mathrm{~L}$ & $1.14(0.88-1.58)$ & $1.13(0.85-1.70)$ & $1.15(0.91-1.37)$ & .67 \\
\hline $\mathrm{FEV}_{1}, \%$ predicted & $46.5(34.1-57.5)$ & $45.4(32.2-60)$ & $47(36-54.5)$ & .80 \\
\hline $\mathrm{FEV}_{1} / \mathrm{FVC}, \%$ & $46.9 \pm 12.1$ & $47.2 \pm 13.7$ & $46.6 \pm 10.8$ & .79 \\
\hline COPD GOLD stage (mild/moderate/severe/very severe), $\%$ & $1 / 35.6 / 34.6 / 28.8$ & $0 / 41.3 / 28.3 / 30.4$ & $1.7 / 31 / 39.7 / 27.6$ & .46 \\
\hline Long-term oxygen therapy, $\%$ & 15.4 & 13.8 & 17 & .63 \\
\hline MMRC dyspnea grade $\geq 2, \%$ & 91.7 & 89.5 & 93.7 & .06 \\
\hline \multicolumn{5}{|l|}{ Exacerbations in the preceding year } \\
\hline Rate, events/subject & 1.39 & 1.37 & 1.41 & .30 \\
\hline Requiring hospitalizations & 0.93 & 1 & 0.87 & .52 \\
\hline \multicolumn{5}{|l|}{ Chronic comorbidities } \\
\hline Congestive heart failure & $28(22.8)$ & $15(25.8)$ & $13(20)$ & .43 \\
\hline Chronic renal failure & $2(1.6)$ & $0(0)$ & $2(3)$ & .17 \\
\hline Diabetes & $20(16.3)$ & $10(17.2)$ & $10(15.3)$ & .74 \\
\hline Non-cirrhotic liver disease & $4(3.3)$ & $2(3.4)$ & $2(3)$ & .90 \\
\hline Neurologic disease & $8(6.5)$ & $3(5.1)$ & $5(7.7)$ & .57 \\
\hline Non-active cancer & $14(11.4)$ & $9(15.5)$ & $5(7.7)$ & .18 \\
\hline \multicolumn{5}{|l|}{ Use of inhaled bronchodilators } \\
\hline Short-acting $\beta_{2}$ agonists & $82(66.7)$ & $34(58.6)$ & $48(73.8)$ & .07 \\
\hline Salbutamol/terbutaline & $76 / 6$ & $32 / 2$ & $44 / 4$ & .67 \\
\hline Long-acting $\beta_{2}$ agonists & $73(59.3)$ & $19(32.7)$ & $54(83)$ & $<.001$ \\
\hline Formoterol/salmeterol & $24 / 49$ & $6 / 13$ & $18 / 36$ & .88 \\
\hline Anticholinergics & $84(68.3)$ & $33(56.8)$ & $51(78.4)$ & .01 \\
\hline Ipratropium/tiotropium & $33 / 51$ & $19 / 14$ & $14 / 37$ & $<.01$ \\
\hline Use of theophylline & $7(5.7)$ & $1(1.7)$ & $6(9.2)$ & .09 \\
\hline \multicolumn{5}{|l|}{$\begin{array}{l}\text { Values are reported as mean } \pm \text { SD, median }(25 \text { th- }-75 \text { th percentiles), or frequency }(\%) \\
\text { GOLD }=\text { Global Initiative for Chronic Obstructive Lung Disease } \\
\text { MMRC = Modified Medical Research Council }\end{array}$} \\
\hline
\end{tabular}

as median (25th-75th percentiles) for continuous variables and as frequency (percentage) for categorical variables.

Differences in continuous variables were analyzed using an independent 2-tailed $t$ test for unpaired analysis; otherwise, the nonparametric Mann-Whitney $U$ test or Kruskal-Wallis test was used. Categorical variables were studied using the chi-square test or the Fisher exact test when necessary.

To define predictors for clinical complications on admission to the hospital (identified by NIV requirement, admission to the ICU, shock, or abnormal mental status), analysis with a univariate and multivariate logistic model was performed with the general characteristics of patients with COPD exacerbation.

Analyses were carried out using a statistical software package (SPSS 17, SPSS, Chicago, Illinois), and $P<.05$ was considered statistically significant.

\section{Results}

Our prospective study cohort included 123 subjects admitted to 2 Spanish university hospitals for COPD exacerbation. Of these, 58 subjects $(47 \%)$ had no inhaled corticosteroid use in their domiciliary therapy, whereas 65 $(53 \%)$ had received inhaled corticosteroid treatment.

Anthropometrics, smoking habit, and functional characteristics were similar in both groups. In terms of domiciliary use of associated bronchodilators, subjects who received inhaled corticosteroids presented considerable use of anticholinergics (78\% of all inhaled corticosteroid users; most prevalent, tiotropium) and long-acting $\beta_{2}$ agonists $(83 \%$ of all inhaled corticosteroid users; most prevalent, salmeterol). The prevalence of subjects using shortacting $\beta_{2}$ agonists and theophylline was similar between groups. The prevalence of comorbidities, exacerbation rates 
occurring in the preceding year, need for long-term oxygen therapy, and dyspnea grade were also similar. Table 1 shows the baseline characteristics of enrolled subjects.

A comparison of clinical, physiological, and laboratory features on admission to the hospital (Table 2) showed that no significant differences between subjects with and without inhaled corticosteroid use. The other variables relating to characteristics of clinical severity $\left(\mathrm{P}_{\mathrm{aCO}}\right.$ with need for NIV support, $\mathrm{P}_{\mathrm{OO}_{2}} / \mathrm{F}_{\mathrm{IO}}$, hospital stay, direct admission to an ICU, abnormal mental status, shock), antibiotic and systemic-corticosteroid treatment (duration [d] and classes of antibiotics used, doses of corticosteroids per subject), prognosis (mortality rate during hospitalization), and risk of a new episode after discharge (readmission rate over a period of $30 \mathrm{~d}$ ) were also comparable between the 2 groups.

The specific etiology and rate of microbiological diagnosis, confirmed in $43 \%$ and $41 \%$ of no-inhaled and inhaled corticosteroid subjects, respectively, were similar between the 2 groups (Table 2).

Assessment of early inflammatory response (Fig. 2) on days 1 and 3 of hospitalization showed similar levels in both groups for all biomarkers collected (C-reactive protein, procalcitonin, IL-1, IL-6, IL-8, and IL-10).

Repetition of the inflammatory pathway analysis, selecting subjects with mild/moderate $(n=45)$ and severe/very severe $(n=78)$ air-flow obstruction, without $(n=71)$ and with $(n=52)$ a recognized infectious etiology, without $(n=39)$ and with $(n=84)$ domiciliary use of anticholinergics, and without $(n=50)$ and with $(n=73)$ domiciliary use of long-acting $\beta_{2}$ agonists (all these data not reported), showed no significant differences between both groups for any of the evaluated biomarkers.

The measurement of biomarkers performed according to type of inhaled corticosteroids used (Fig. 3) showed lower levels of IL-8 on day 1 in subjects who used fluticasone $(n=36)$ compare with those who used budesonide ( $n=29$; median $0[0-7.5]$ vs 16 [1.5-32], respectively, $P<.01)$.

The logistic regression model (Table 3) performed using clinical complications on hospitalization as a dependent variable (presence/absence of NIV requirement, direct admission to an ICU, shock, or abnormal mental status) shows the severity of COPD (severe/very severe vs mild/moderate) as the only predictive factor in the multivariate analysis (odds ratio 3.13, standard error $0.51,95 \% \mathrm{CI}$ $1.13-8.63, P=.02)$.

\section{Discussion}

In summary, the main findings of our observational study refer to a lack of influence of inhaled corticosteroids in the early inflammatory response to COPD exacerbation. Indeed, on days 1 and 3 of hospitalization, serum levels of biomarkers were similar in inhaled corticosteroid users and those who did not use inhaled corticosteroids. In inhaled corticosteroid users, fluticasone produced lower levels of IL-8 compared with budesonide.

The clinical presentation and severity of COPD exacerbation, infectious etiology, hospital mortality, and readmission over a $30-\mathrm{d}$ period were similar in the 2 groups. Furthermore, air-flow obstruction of COPD was the only predictive factor in the occurrence of complications on admission to the hospital (need for NIV, need for ICU admission, shock, abnormal mental status).

Inhaled corticosteroids are anti-inflammatory medications that are widely used in COPD patients, but their clinical response is often relatively poor, ${ }^{22}$ with failure to reduce levels of key COPD-related inflammatory cells $\left(\mathrm{CD}^{+} \mathrm{T}\right.$ lymphocytes, neutrophils) and the interaction suppression of cytokine relapse $\mathrm{e}^{23-25}$ after stimuli. As documented in peripheral lung tissue, alveolar macrophages, and bronchial biopsy specimens of COPD patients, a molecular mechanism of steroid resistance may be due to reduced levels of histone deacetylase-2 activity ${ }^{26-28}$; this is a nuclear enzyme involved in corticosteroid deactivation of pro-inflammatory genes and in the repression of cytokine production. We hypothesized that the lack of a modulation effect of inhaled corticosteroids with similar serum levels of biomarkers on admission in inhaled and no-inhaled corticosteroid subjects (see Fig. 2) may represent a biological effect of steroid resistance with an undetectable down-regulation effect of inhaled corticosteroids. Moreover, the repetition of the inflammatory comparative analyses according to stratification of air-flow obstruction severity, presence of infectious etiology, and domiciliary use of anticholinergics or long-acting $\beta_{2}$ agonists appears not to affect this inflammatory pathway in both groups. However, very large studies are required to confirm our results.

Due to different pharmacokinetic properties, the evaluation of 2 different types of inhaled corticosteroids (see Fig. 3) demonstrated that, on day 1, fluticasone produced a lower inflammatory response than budesonide in IL-8 levels only. This observation confirms an in vitro study ${ }^{29}$ on human lung epithelial cells and alveolar macrophages, in which both inhaled corticosteroids caused a dose-dependent inhibition of pro-inflammatory cytokine relapse (in particular, IL-8), but fluticasone was $\sim 10$ times more potent than budesonide in terms of suppression capacity. We do not know what this difference means in clinical practice, but, at least in this study, we observed no clinical, microbiological, or evolutive differences.

Following the biological findings, the current perspective that our study adds to the knowledge of COPD exacerbation is the demonstration that inhaled corticosteroids, used until onset of exacerbation, do not influence the clinical presentation or severity of the clinical course (see Table 2). Moreover, the frequency of confirmed infectious cases and microbiological etiology were similar in subjects with and without use 


\section{INFLUENCE OF INHALED CORTICOSTEROIDS IN COPD EXACERBATION}

Table 2. Clinical Presentation, Laboratory Data, Microbiological Diagnosis, and Outcomes of Study Cohort

\begin{tabular}{|c|c|c|c|}
\hline Variables & $\begin{array}{l}\text { No-Inhaled } \\
\text { Corticosteroid } \\
\text { Subjects }\end{array}$ & $\begin{array}{c}\text { Inhaled } \\
\text { Corticosteroid } \\
\text { Subjects }\end{array}$ & $P$ \\
\hline Fever, $\%$ & 27.6 & 36.2 & .25 \\
\hline Chills, \% & 20.7 & 35.4 & .34 \\
\hline Cough, $\%$ & 82.8 & 71.9 & .78 \\
\hline $\begin{array}{l}\text { Characteristics of sputum } \\
\quad \text { (absence/mucus/purulence/rusty), \% }\end{array}$ & $31 / 46.6 / 20.7 / 1.7$ & $36.9 / 53.8 / 7.7 / 1.5$ & .59 \\
\hline $\begin{array}{l}\text { Classification of COPD exacerbations according to } \\
\text { Anthonisen criteria (type I/type II/type III), \% }\end{array}$ & $46.3 / 29.6 / 24.1$ & $33.9 / 27.4 / 38.7$ & .52 \\
\hline Breathing frequency, breaths/min & $24(20-30)$ & $24(20-30)$ & .89 \\
\hline Heart rate, beats/min & $95(80-100)$ & $95(80-102)$ & .88 \\
\hline Systolic blood pressure, $\mathrm{mm} \mathrm{Hg}$ & $140(120-164)$ & $147(130-162.5)$ & .51 \\
\hline Diastolic blood pressure, $\mathrm{mm} \mathrm{Hg}$ & $80(71-90)$ & $80(69.5-90)$ & .72 \\
\hline White blood cells, count $\times 10^{3}$ cells $/ \mathrm{L}$ & $10.40(7.50-13.40)$ & $8.70(6.55-11.80)$ & .49 \\
\hline Hematocrit, $\%$ & $45.1(43-50)$ & $45.7(43-49)$ & .62 \\
\hline Glycemia, mg/dL & $118.77(93.8-166)$ & $117(103.5-143.8)$ & .82 \\
\hline Creatinine, $\mathrm{mg} / \mathrm{dL}$ & $1(0.9-1.3)$ & $0.9(0.8-1.1)$ & .28 \\
\hline Serum sodium, $\mathrm{mmol} / \mathrm{L}$ & $136(133-139)$ & $138(134.9-139.9)$ & .37 \\
\hline Serum potassium, $\mathrm{mEq} / \mathrm{L}$ & $4.5(4.2-5.1)$ & $4.4(4-4.7)$ & .36 \\
\hline $\mathrm{pH}$ & $7.39(7.35-7.41)$ & $7.40(7.37-7.43)$ & .42 \\
\hline $\mathrm{P}_{\mathrm{aCO}_{2}}, \mathrm{~mm} \mathrm{Hg}$ & $47(42-56)$ & $47(40.9-59)$ & .75 \\
\hline $\mathrm{P}_{\mathrm{aO}_{2}} / \mathrm{F}_{\mathrm{IO}_{2}}$ & $261.9(233.3-279.5)$ & $257.1(211.9-280.9)$ & .54 \\
\hline Bicarbonate, $\mathrm{mmol} / \mathrm{L}$ & $28(25-33)$ & $29(26-32)$ & .58 \\
\hline Base excess, mmol/L & $2.7(0.7-4.9)$ & $3.9(2-6.4)$ & .37 \\
\hline Etiological diagnosis confirmed* & $25(43)$ & $27(41)$ & .97 \\
\hline Streptococcus pneumoniae, $\%$ & 4 & 11.1 & .61 \\
\hline Streptococcus viridans, $\%$ & 12 & 14.8 & .97 \\
\hline Staphylococcus aureus, \% & 8 & 3.7 & .65 \\
\hline Haemophilus influenzae, \% & 24 & 22.2 & .97 \\
\hline Haemophilus parainfluenzae, $\%$ & 0 & 11.1 & .40 \\
\hline Pseudomonas aeruginosa, $\%$ & 20 & 25.9 & .37 \\
\hline Moraxella catarrhalis, $\%$ & 4 & 0 & .48 \\
\hline Chlamydia pneumoniae, $\%$ & 4 & 0 & .48 \\
\hline Enterobacteriaceae $\dagger, \%$ & 8 & 7.4 & .97 \\
\hline Acinetobacter subspecies, $\%$ & 8 & 3.7 & .65 \\
\hline Aspergillus niger, $\%$ & 4 & 0 & .48 \\
\hline Legionella pneumophila, \% & 4 & 0 & .48 \\
\hline Hospital stay, d & $6(4-13)$ & $6(4-8.5)$ & .83 \\
\hline Use of systemic corticosteroids, \% & 79.3 & 84.6 & .68 \\
\hline Doses of systemic corticosteroids per subject, mg & 321.3 & 300.8 & .49 \\
\hline Use of antibiotics, $\%$ & 77.5 & 81.5 & .89 \\
\hline Duration of antibiotic treatment, $\mathrm{d}$ & $6(0-8)$ & $6(4-9)$ & .75 \\
\hline $\begin{array}{l}\text { No. of classes of antibiotics used, } \\
\% \text { one class } / \geq 2 \text { classes } \$\end{array}$ & $65.2 / 34.8$ & $76.3 / 23.7$ & .34 \\
\hline NIV required, \%§ & 6.8 & 9.2 & .74 \\
\hline ICU required, \%§ & 5.1 & 6.1 & .89 \\
\hline Shock, $\% \S$ & 3.4 & 3 & .96 \\
\hline Mental status alteration, $\% \S$ & 6.8 & 10.7 & .53 \\
\hline Mortality during hospitalization, $\%$ & 6.8 & 1.5 & .18 \\
\hline Readmission in a $30-\mathrm{d}$ period after discharge, $\%$ & 22.4 & 23.1 & .95 \\
\hline
\end{tabular}

Values are reported as median (25th-75th percentiles) or as frequency (\%). For microbiological data, values are reported as percentage related to the number of subjects with confirmed etiological diagnosis in each group.

* Percentage calculated for total subjects in each group

$\dagger$ Including Escherichia coli and Proteus mirabilis

$\$$ Calculated in subjects using antibiotics

$\S$ Outcomes evaluated on admission to the hospital 

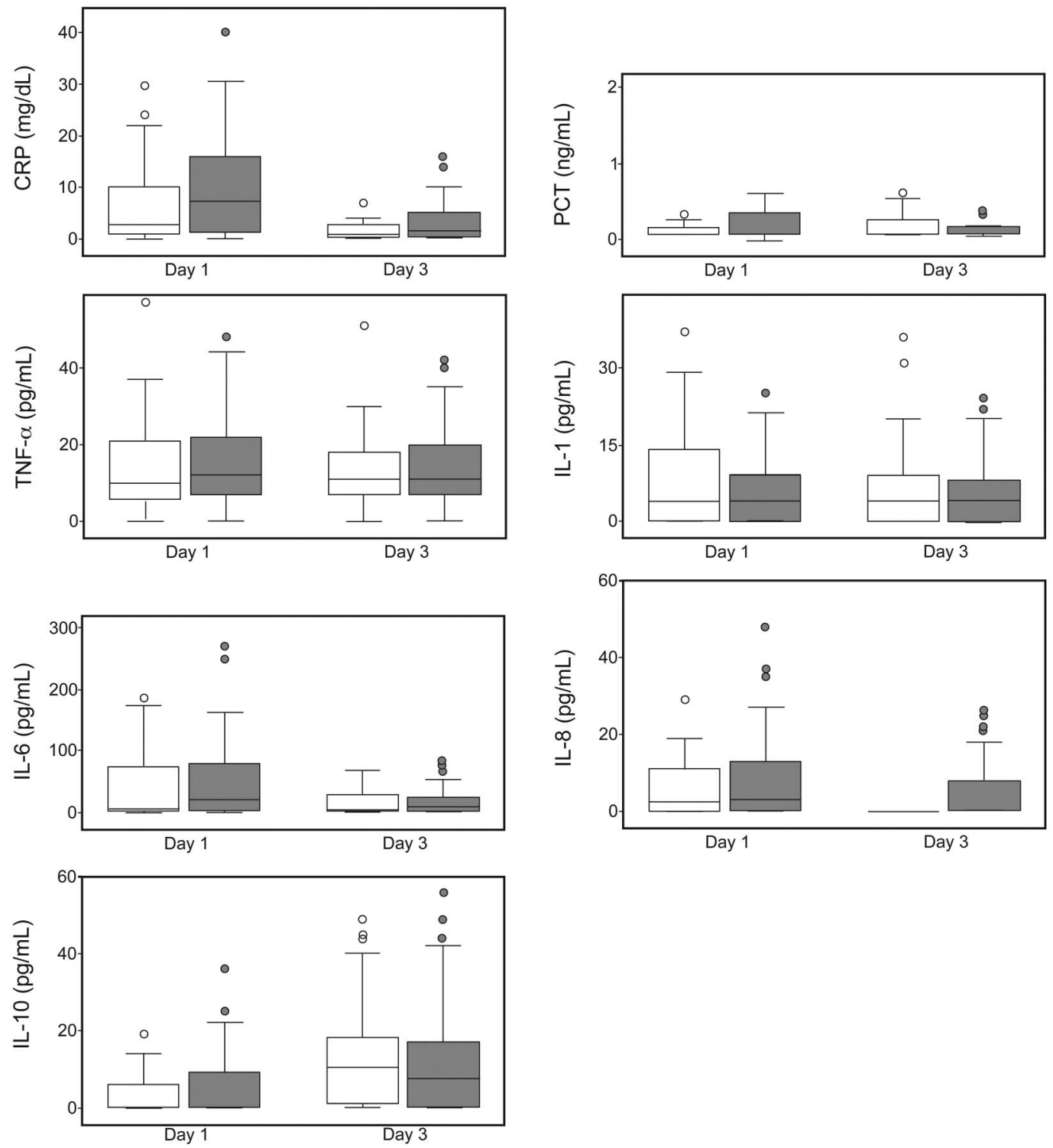

Fig. 2. Panel of inflammatory response according to use of corticosteroids at onset of COPD exacerbation. White and grey box plots represent no-inhaled and inhaled corticosteroid subjects with COPD exacerbation, respectively. The horizontal bar and box length represent the median and the 25th-75th percentiles, respectively. Circles indicate outliers. CRP $=$ C-reactive protein; PCT $=$ procalcitonin; TNF- $\alpha=$ tumor necrosis factor alpha; IL $=$ interleukin.

of inhaled corticosteroids (see Table 2). Although the use of inhaled corticosteroids in COPD patients has been demonstrated to be useful in the reduction of exacerbation events ${ }^{16,17}$ and in protection against the development of complicated forms of hospitalized community-acquired pneumonia. ${ }^{14,15}$ On the other hand, the long-term use of inhaled corticosteroids increases the risk of pneumonia, ${ }^{18-20}$ especially with fluticasone. ${ }^{20}$ Our study, performed in subjects with COPD exacerbation but without pneumonia, demonstrates that inhaled corticosteroids have no detrimental effect on the devel- opment of complications on admission or in other outcomes collected during the clinical course.

In the evaluation of general characteristics that are useful for predicting the occurrence of complications on admission to the hospital (see Table 3), we have shown that inhaled corticosteroids had no significant effects. In contrast, we found that the number of comorbidities ( 2 or more comorbidities added to COPD vs 0 comorbidities) and the COPD GOLD stage (severe/very severe vs mild/ moderate) were both negative predictive factors in univar- 

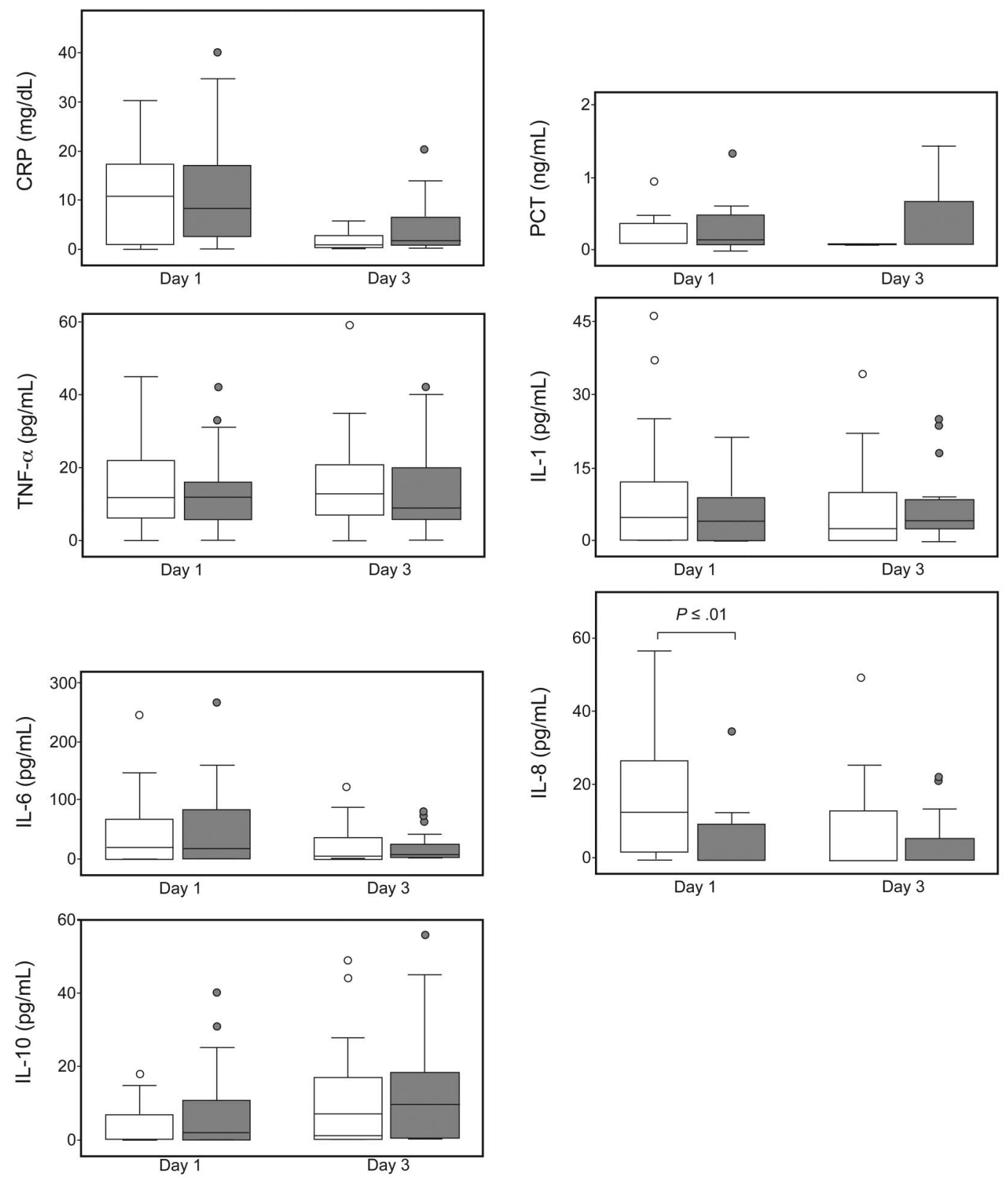

Fig. 3. Panel of inflammatory response according to different types of inhaled corticosteroids. Analysis was performed only on subjects who received inhaled corticosteroids $(n=65)$. White and grey box plots represent subjects who used budesonide $(n=29)$ and fluticasone $(n=36)$, respectively. The horizontal bar and box length represent the median and the 25 th- 75 th percentiles, respectively. Circles indicate outliers. CRP $=$ C-reactive protein; PCT $=$ procalcitonin; TNF- $\alpha=$ tumor necrosis factor alpha; $\mathrm{IL}=$ interleukin.

iate analysis. However, in multivariate analysis, the COPD GOLD stage was the only independent predictive factor. This is probably explained by the high co-variation effect between these factors (Pearson $\mathrm{r}=0.31, P<.001$ ). Our predictive analysis confirms prior results showing that COPD severity (measured by $\left.\mathrm{FEV}_{1}\right)^{30-32}$ and the Charlson comorbidity index ${ }^{32}$ are variables in exacerbated patients that correlate with detrimental effects on return to preexacerbation health status, ${ }^{30}$ that are independently associated with antibiotic failure, ${ }^{31}$ and that are related to stay and other short-term prognosis factors. ${ }^{32}$ Although significant statistical evidence was not found, a negative trend for the use of steroids (inhaled and systemic) as concomitant medications in hospitalized patients with COPD exacerbation was shown to influence clinical cure ${ }^{31}$ and treatment failure ${ }^{32}$; however, in both studies, this observation was not the primary aim but was associated with determination of antibiotic effectiveness evaluated during the clinical course and after a COPD exacerbation event, but not at onset of COPD exacerbation. 
Table 3. Univariate and Multivariate Logistic Regression Analyses Performed to Define Variables Predicting Clinical Complications on Admission to the Hospital

\begin{tabular}{|c|c|c|c|c|c|c|c|c|}
\hline Risk Factors & OR & SE & $95 \% \mathrm{CI}$ & $P$ & OR & SE & $95 \% \mathrm{CI}$ & $P$ \\
\hline Age (older vs younger)* & 1.50 & 0.43 & $0.64-3.51$ & .35 & & & & \\
\hline $\begin{array}{l}\text { COPD GOLD stage (severe/very severe vs } \\
\text { mild/moderate) }\end{array}$ & 3.06 & 0.48 & $1.17-7.97$ & .02 & 3.13 & 0.51 & $1.13-8.63$ & .02 \\
\hline \multicolumn{9}{|l|}{ Anthonisen criteria } \\
\hline Type I vs type III & 1.30 & 0.48 & $0.50-3.38$ & .58 & & & & \\
\hline Type II vs type III & 1.17 & 0.53 & $0.41-3.31$ & .76 & & & & \\
\hline \multicolumn{9}{|l|}{ Chronic comorbidities, No. } \\
\hline 1 vs 0 & 1.04 & 0.45 & $0.43-2.53$ & .91 & 0.66 & 0.50 & $0.24-1.80$ & .42 \\
\hline$\geq 2$ vs 0 & 3.55 & 0.60 & $1.08-11.6$ & .03 & 1.84 & 0.65 & $0.50-6.67$ & .35 \\
\hline Etiological diagnosis confirmed (yes vs no) & 1.46 & 0.39 & $0.67-3.19$ & .33 & & & & \\
\hline Use of inhaled corticosteroids (yes vs no) & 1.39 & 0.40 & $0.64-3.06$ & .40 & & & & \\
\hline Use of short-acting $\beta_{2}$ agonists (yes vs no) & 1.18 & 0.42 & $0.51-2.73$ & .69 & & & & \\
\hline Use of long-acting $\beta_{2}$ agonists (yes vs no) & 0.80 & 0.40 & $0.36-1.77$ & .59 & & & & \\
\hline Use of anticholinergics (yes vs no) & 1.55 & 0.44 & $0.64-3.74$ & .32 & & & & \\
\hline $\begin{array}{l}\text { Use of long-acting } \beta_{2} \text { agonists }+ \text { inhaled } \\
\text { corticosteroids (yes vs no) }\end{array}$ & 1.71 & 0.56 & $0.57-5.16$ & .33 & & & & \\
\hline $\begin{array}{l}\text { Use of anticholinergics }+ \text { inhaled corticosteroids } \\
\text { (yes vs no) }\end{array}$ & 1.34 & 0.39 & $0.61-2.91$ & .45 & & & & \\
\hline Use of theophylline (yes vs no) & 0.85 & 0.86 & $0.16-4.63$ & .85 & & & & \\
\hline $\begin{array}{l}\text { Clinical complications on admission to the hospital were identifiec } \\
\text { status alteration. } \\
* 65 \text { y defined as the cutoff } \\
\mathrm{OR}=\text { odds ratio } \\
\mathrm{SE}=\text { standard error } \\
\mathrm{GOLD}=\text { Global Initiative for Chronic Obstructive Lung Disease }\end{array}$ & e presenc & eed for $n$ & asive ventilation & ir direc & ssion to $t$ & , direct II & mission, shock, & \\
\hline
\end{tabular}

To the best of our knowledge, our study is the first investigating the role of corticosteroids in the early inflammatory response and clinical presentation of subjects with COPD exacerbation. Nevertheless, our study has some limitations that need to be addressed. First, the baseline inflammation levels and the dosage and time period of inhaled corticosteroid use were not recorded by us; for this reason, we can rule out a possible inflammatory pattern of response related to these factors. ${ }^{33}$ Second, in white blood cell counts, data on the number of eosinophils were not collected; new research has found that these blood cells define a specific biologic cluster of patients with COPD exacerbation ${ }^{34}$ and directly link corticosteroid treatment to exacerbation. ${ }^{35}$

In conclusion, our study suggests that, in COPD patients, chronic use of inhaled corticosteroids does not influence per se the early inflammatory response to COPD exacerbation. Moreover, clinical features on admission and during the course of the exacerbation and the infectious etiology of COPD exacerbation were similar in subjects with or without inhaled corticosteroid use. Baseline severity of COPD predicts the clinical complications on admission for COPD exacerbation.

\section{REFERENCES}

1. Global Initiative for Chronic Obstructive Pulmonary Disease. Global strategy for the diagnosis, management, and prevention of chronic obstructive pulmonary disease. Updated 2013. http://www. goldcopd.org/guidelines-global-strategy-for-diagnosismanagement.html. Accessed June 4, 2014.

2. Anthonisen NR, Manfreda J, Warren CP, Hershfield ES, Harding GK, Nelson NA. Antibiotic therapy in exacerbations of chronic obstructive pulmonary disease. Ann Intern Med 1987;106(2):196-204.

3. Sullivan SD, Ramsey SD, Lee TA. The economic burden of COPD. Chest 2000;117(2 Suppl):5S-9S.

4. Donaldson GC, Seemungal TA, Bhowmik A, Wedzicha JA. Relationship between exacerbation frequency and lung function decline in chronic obstructive pulmonary disease. Thorax 2002;57(10):847852 .

5. Seemungal TA, Donaldson GC, Paul EA, Bestall JC, Jeffries DJ, Wedzicha JA. Effect of exacerbation on quality of life in patients with chronic obstructive pulmonary disease. Am J Respir Crit Care Med 1998;157(5 Pt 1):1418-1422.

6. Soler-Cataluña JJ, Martínez-García MA, Román Sánchez P, Salcedo E, Navarro M, Ochando R. Severe acute exacerbations and mortality in patients with chronic obstructive pulmonary disease. Thorax 2005; 60(11):925-931.

7. Papi A, Bellettato CM, Braccioni F, Romagnoli M, Casolari P, Caramori G, et al. Infections and airway inflammation in chronic obstructive pulmonary disease severe exacerbations. Am J Respir Crit Care Med 2006;173(10):1114-1121. 


\section{INFLUENCE OF INHALED CORTICOSTEROIDS IN COPD EXACERBATION}

8. Di Stefano A, Turato G, Maestrelli P, Mapp CE, Ruggieri MP, Roggeri A, et al. Airflow limitation in chronic bronchitis is associated with T-lymphocyte and macrophage infiltration of the bronchial mucosa. Am J Respir Crit Care Med 1996;153(2):629-632.

9. Hurst JR, Perera WR, Wilkinson TM, Donaldson GC, Wedzicha JA. Systemic and upper and lower airway inflammation at exacerbation of chronic obstructive pulmonary disease. Am J Respir Crit Care Med 2006;173(1):71-78

10. Koutsokera A, Stolz D, Loukides S, Kostikas K. Systemic biomarkers in exacerbations of COPD: the evolving clinical challenge. Chest 2012;141(2):396-405.

11. Perera WR, Hurst JR, Wilkinson TM, Sapsford RJ, Müllerova H, Donaldson GC, Wedzicha JA. Inflammatory changes, recovery and recurrence at COPD exacerbation. Eur Respir J 2007;29(3):527-534.

12. Sin DD, Lacy P, York E, Man SF. Effects of fluticasone on systemic markers of inflammation in chronic obstructive pulmonary disease. Am J Respir Crit Care Med 2004;170(7):760-765.

13. Calverley PMA, Barnes PJ. Pro/con editorials: inhaled corticosteroids are/are not beneficial in chronic obstructive pulmonary disease. Am J Respir Crit Care Med 2000;161(2 Pt 1):341-344.

14. Chen D, Restrepo MI, Fine MJ, Pugh MJ, Anzueto A, Metersky ML, et al. Observational study of inhaled corticosteroids on outcomes for COPD patients with pneumonia. Am J Respir Crit Care Med 2011; 184(3):312-316.

15. Sellares J, López-Giraldo A, Lucena C, Cilloniz C, Amaro R, Polverino $\mathrm{E}$, et al. Influence of previous use of inhaled corticoids on the development of pleural effusion in community-acquired pneumonia. Am J Respir Crit Care Med 2013;187(11):1241-1248.

16. Burge PS, Calverley PM, Jones PW, Spencer S, Anderson JA, Maslen TK. Randomised, double blind, placebo controlled study of fluticasone propionate in patients with moderate to severe chronic obstructive pulmonary disease: the ISOLDE trial. BMJ 2000;320(7245): 1297-303.

17. Vestbo J, Sørensen T, Lange P, Brix A, Torre P, Viskum K. Longterm effect of inhaled budesonide in mild and moderate chronic obstructive pulmonary disease: a randomised controlled trial. Lancet 1999;353(9167):1819-1823.

18. Singh S, Amin AV, Loke YK. Long-term use of inhaled corticosteroids and the risk of pneumonia in chronic obstructive pulmonary disease: a meta-analysis. Arch Intern Med 2009;169(3):219-229.

19. Drummond MB, Dasenbrook EC, Pitz MW, Murphy DJ, Fan E. Inhaled corticosteroids in patients with stable chronic obstructive pulmonary disease: a systematic review and meta-analysis. JAMA 2008;300(20):2407-2416

20. Suissa S, Patenaude V, Lapi F, Ernst P. Inhaled corticosteroids in COPD and the risk of serious pneumonia. Thorax 2013;68(11):10291036.

21. Quanjer PH, Tammeling GJ, Cotes JE, Pedersen OF, Peslin R, Yernault JC. Lung volumes and forced ventilatory flows: report Working Party Standardization of Lung Function Tests, European Community for Steel and Coal. Official statement of the European Respiratory Society. Eur Respir J Suppl 1993;16:5-40.
22. Soriano JB, Sin DD, Zhang X, Camp PG, Anderson JA, Anthonisen $\mathrm{NR}$, et al. A pooled analysis of $\mathrm{FEV}_{1}$ decline in COPD patients randomized to inhaled corticosteroids or placebo. Chest 2007;131(3): 682-689.

23. Culpitt SV, Rogers DF, Shah P, De Matos C, Russell RE, Donnelly LE, Barnes PJ. Impaired inhibition by dexamethasone of cytokine release by alveolar macrophages from patients with chronic obstructive pulmonary disease. Am J Respir Crit Care Med 2003;167(1): 24-31.

24. Hattotuwa KL, Gizycki MJ, Ansari TW, Jeffery PK, Barnes NC. The effects of inhaled fluticasone on airway inflammation in chronic obstructive pulmonary disease: a double-blind, placebo-controlled biopsy study. Am J Respir Crit Care Med 2002;165(12):1592-1596.

25. Loppow D, Schleiss MB, Kanniess F, Taube C, Jörres RA, Magnussen H. In patients with chronic bronchitis a four week trial with inhaled steroids does not attenuate airway inflammation. Respir Med 2001;95(2):115-121.

26. Ito K, Barnes PJ, Adcock IM. Glucocorticoid receptor recruitment of histone deacetylase 2 inhibits interleukin- $1 \beta$-induced histone $\mathrm{H} 4$ acetylation on lysines 8 and 12. Mol Cell Biol 2000;20(18):6891-903.

27. Barnes PJ, Ito K, Adcock IM. Corticosteroid resistance in chronic obstructive pulmonary disease: inactivation of histone deacetylase. Lancet 2004;363(9410):731-733.

28. Ito K, Ito M, Elliott WM, Cosio B, Caramori G, Kon OM, et al. Decreased histone deacetylase activity in chronic obstructive pulmonary disease. N Engl J Med 2005;352(19):1967-1976.

29. Ek A, Larsson K, Siljerud S, Palmberg L. Fluticasone and budesonide inhibit cytokine release in human lung epithelial cells and alveolar macrophages. Allergy 1999;54(7):691-699.

30. Wilson R, Jones P, Schaberg T, Arvis P, Duprat-Lomon I, Sagnier PP, MOSAIC Study Group. Antibiotic treatment and factors influencing short and long term outcomes of acute exacerbations of chronic bronchitis. Thorax 2006;61(4):337-342.

31. Dewan NA, Rafique S, Kanwar B, Satpathy H, Ryschon K, Tillotson GS, Niederman MS. Acute exacerbation of COPD: factors associated with poor treatment outcome. Chest 2000;117(3):662-671.

32. Almagro P, Cabrera FJ, Diez J, Boixeda R, Alonso Ortiz MB, Murio $\mathrm{C}$, et al. Comorbidities and short-term prognosis in patients hospitalized for acute exacerbation of COPD: the EPOC en Servicios de Medicina Interna (ESMI) study. Chest 2012;142(5):1126-1133.

33. Agustí A, Edwards LD, Rennard SI, MacNee W, Tal-Singer R, Miller BE, et al. Persistent systemic inflammation is associated with poor clinical outcomes in COPD: a novel phenotype. PLoS ONE 2012;7(5):e37483.

34. Bafadhel M, McKenna S, Terry S, Mistry V, Reid C, Haldar P, et al. Acute exacerbations of chronic obstructive pulmonary disease: identification of biologic clusters and their biomarkers. Am J Respir Crit Care Med 2011;184(6):662-671.

35. Bafadhel M, McKenna S, Terry S, Mistry V, Pancholi M, Venge P, et al. Blood eosinophils to direct corticosteroid treatment of exacerbations of chronic obstructive pulmonary disease: a randomized placebo-controlled trial. Am J Respir Crit Care Med 2012;186(1): 48-55. 